\title{
The cultivation of college students in Japanese major self-learning ability
}

\author{
Zhang Hui , Xiao Liangdong \\ Jingdezhen Ceramic University ${ }^{1}$
}

\begin{abstract}
Key words: Colleges and universities; Japanese professional; Student; Self-study ability; Culture Abstract: As one of the important positions in the field of talents cultivation, Japanese major is one of the important foreign language majors in colleges and universities. Different from other non-language majors, Japanese teaching has high demands on students' practical ability and applying ability. As Japanese and Chinese language habits and logic are different, learning Japanese basically rely on consciousness. In this paper, starting from the actual situation of Japanese professional teaching, to cultivate students' self-study ability put forward scientific advice, so as to help students master the effective method of self-study, a breakthrough in Japanese learning.
\end{abstract}

\section{Introduction}

With the deepening of the new curriculum reform and the concept of quality teaching, the reform of colleges and universities is in full swing. The traditional teaching methods can not meet the demands of students and is not conducive to linking with the market. The new "project-oriented, task-driven" teaching method has become the focus of attention. At present, the continuous expansion of colleges and universities, the number of students continued to increase, the Japanese professional has always been the main professional content, but also the main channel for training translation talents and economic communication talents in China. By the traditional ideas, Many universities in China ignore the cultivation of students' self-study ability, the teaching method is single, the lack of innovation, and the practical ability of graduates is not good and unable to adapt to market demand for Japanese professional talents. The so-called self-study ability, is the student independent inquiry and initiative of learning, help students become passive learning into active learning. In view of the insufficiency of Japanese professional teaching, universities must pay attention to the cultivation of student's self-study ability, to carry out the strict teaching plan, arouse their learning enthusiasm, and master the methods of effective learning.

\section{What is self-study ability?}

As the name suggests, Self-study ability is refers to the ability of autonomous learning, is short fort and active participation of students learning. In general, self-study ability includes self-study and autonomous learning, the coordinated development of the two is the key to improving self-study ability.

Conscious learning ability is closely related to interests, hobbies and habits, the leader of the teachers for teaching, in teaching in colleges and universities should have a comprehensive knowledge of students, stimulate students' interest in learning, from the traditional classroom "want me to learn" into a new class of "I want to learn", then the students' interest into stable learning habit gradually, and have a lasting power, conscious learning knowledge.

Self-study ability is the concept of the famous American linguist Zimmerman, the so-called self-study refers to the autonomy of students to control and adjust learning time, the ability to develop learning plans, and according to time changes reasonable arrangements for learning content, let the student become more efficient. Generally speaking, self-study ability refers to the ability of students to turn their hobbies into continuous learning activities, in the accumulation of slowly establish learning goals, will learn to cure as a habit. In the actual learning process, can also be based on different situations in a timely manner to change plans, develop their own learning methods and goals, to mobilize their own initiative, and gradually improve the efficiency of learning.

\footnotetext{
1 Zhang Hui (1985.08 -), female, Hubei Wuxue people, Jingdezhen Ceramic University teachers, Xiao Liangdong (1975.10-), male, Jiangxi Huichang, Jingdezhen Ceramic University teachers
} 


\section{The Necessity of Cultivating Japanese Majors' Self - study Ability in Universities 3.1Help to stimulate students' interest in learning}

Teaching is a two-way interaction between teachers and students, relying on either party can not guarantee high-quality learning, through the cultivation of students' self-learning ability, to mobilize their enthusiasm for learning, to play their subjective initiative and in the accumulation of learning aims.

\subsection{Help improve the Japanese level of students}

Japanese professional is a kind of language learning, different from other specialties, language need to accumulate, learning content is more, students need to reverse thinking, separate the Chinese and Japanese. As a high quality of learning, practice, repeated exercises, more talk, listen more, say more is the science of learning. Cultivate the students' self-study ability, can let them keep good state of mind, don't let up in the process of learning don't let up, to find time to practice and through the accumulation of constantly improve the level of the Japanese.

\subsection{Help with classroom teaching complement each other}

Classroom teaching more professional knowledge explained in Japanese is given priority to, class time is very limited, the vocabulary recite dialogue, grammar practice relies on accumulation after class, teachers simply can not meet the teaching objectives. Therefore, cultivate the students' self-Study ability, can build an interactive classroom, to implement complementary in class and after class and highlights the advantage of after class teaching, improve the quality of student learning.

\section{Measures for Cultivating Japanese Majors' Self - study Ability in Colleges and Universities}

\subsection{Based on interest, creating a relaxed and pleasant Japanese learning atmosphere}

It is understand that Japanese students choose a lot because they like the Japanese animation, drama, games, etc., so they want to learn some Japanese, and development interests. For this part of the students, you can ask them to introduce their favorite Japanese anime or TV content and excerpts from the appropriate clips to play, teach Japanese drama theme song and popular Japanese songs, making simple Japanese cuisine, try the traditional Japanese clothing, Japan's performance in the grand sporting events, and hot news from Japan and so on. Through these happy teaching method, strengthen of the words and sentence patterns in the teaching process, and in the process of the teaching activities, nature will also be attracted to the other students, so as to improve the learning interest of all students, let them learn Japanese knowledge in a pleasant atmosphere.

\subsection{Formulate a scientific plan for autonomous learning}

It is not a simple process to cultivate students 'ability of autonomous learning. It requires a long period of accumulation and constant exercise. It makes plans for Japanese language learning, combines their own situation with learning, to develop students good study habits and cultivate self-study ability has a positive effect. In this regard, teachers should guide students in accordance with their time reasonable arrangements for learning content, for their weak links to strengthen learning, in major examinations before the purpose of a breakthrough, to develop good study habits. 4.3According to the cognitive characteristics of students and the law of Japanese learning, students develop effective learning methods

"Teaching, the teaching, is teaching students to learn", to effectively improve the students' Japanese self-study ability, we must teach them how to self-study. Japanese learning is not only by rote, as long as the master of effective learning methods, will be able to receive better learning results. Teachers to teach students an effective memory method, to fully mobilize the various sensory organs, while reading and writing to remember, according to the forgotten curve to consolidate learning.

\subsection{Guide students to use the tool properly}

Guide and encourage students to use the library, the Internet, foreign language newspapers, magazines and other information resources to expand their knowledge, while the completion of the corresponding tasks. For example, the organization of qualified students landing HJ Japanese Web, to complete their interest in learning tasks, while the accumulation of Shanghai yuan, to the end of 
each month to see who earned more than Shanghai yuan, organize a reading group, reading Japanese newspapers and magazines, and excerpts of their favorite sentences regularly recite the exchange, organization of a Japanese culture research group, through the search for information, a week to introduce a unique Japanese social and cultural phenomenon.

\section{Conclusion}

Autonomous learning is the inevitable outcome of the deepening teaching reform, this kind of study way the import of Japanese professional teaching practice, can guide the student to have the independent learning ability, the students have a profound effect on work and life in the future. Japanese professional belongs to linguistics, expression ability, practice ability of students have very high demand, combined with shortcomings in the course of the past teaching, teachers should have a purpose and plans to implement teaching, create a good learning atmosphere, let them develop scientific study plan based on the characteristics of students, master the methods of effective learning, and outstanding technology advantage, and through independent learning to learn Japanese.

\section{Acknowledgement}

This paper is the result of the teaching reform and research project of Jingdezhen Ceramic University in 2015 (the subject self-organizing fund number 212050-007). The results of the research on the teaching mode of "Japanese translation" micro-teaching + flip classroom "

\section{References}

[1] Yu Yong. Japanese Literature Teaching in Japanese Universities and Cultivating Intercultural Communicative Competence of College Students [J]. Heilongjiang Science and Technology Information, 2013,05: 173.

[2] Cui Jihua. Try to talk about the Japanese students comprehensive ability training [J]. Journal of Jiangsu polytechnic institute (social science edition), 2008, 114: 114-117.

[3] Lin Shanshan. Improve private colleges by gradation teaching Japanese students communication skills - in Heilongjiang institute of foreign languages, for example [A]. Higher education institute in Heilongjiang province. Inheritance and innovation, improving the quality of higher education [C ]. Higher education society in Heilongjiang province, 2014-6.

[4] Wu Yanli. Basic Japanese course to improve students' application ability, strengthen the cultivation of research methods and way to Japanese students application ability [J]. Journal of vocational and technical college, Harbin, 01 2015: 110-111.

[5] Zou Wei. On the reform and innovation of the teaching model of the Japanese major [A]. "Decision-making and information" magazine, Peking University School of Economics and Management. "Decision Forum - Management Science and Management Decision Seminar" (On) [C]. "Decision-making and information" magazine, Peking University School of Economics and Management :, 2016: 1. 